D.O.I.: $10.3895 / \mathrm{S} 1808-04482008000100012$

\title{
TECNOLOGIA NA CADEIA PRODUTIVA BOVINA INTERNACIONAL: O USO DA RFID NA RASTREABILIDADE DA CARNE BOVINA
}

\section{TECHNOLOGY IN THE INTERNATIONAL CATTLE CHAIN: THE USE OF RADIO FREQUENCY IDENTIFICATION IN CATTLE TRACEABILITY}

\author{
Priscilla Cristina Cabral Ribeiro ${ }^{1}$; Annibal José Scavarda ${ }^{2}$; Mário Otávio Batalha ${ }^{3}$ \\ ${ }^{1}$ Universidade Federald e Ouro Preto e Universidade Federal de São Carlos - UFOP - UFSCar - \\ Ouro Preto/SãoCarlos - Brasil - priscilla@depro.em.ufop.br \\ ${ }^{2}$ School of Management, Royal Melbourne Institute of Technology University - Melbourne - \\ Austrália - annibal@rdc.puc-rio.br \\ ${ }^{3}$ Universidade Federal de São Carlos - UFSCar - São Carlos - Brasil- dmob@power.ufscar.br
}

\begin{abstract}
Resumo
Este artigo tem por objetivo discutir a Identificação por Rádio Freqüencia (Radio Frequency Identification - RFID) para a rastreabilidade da cadeia produtiva internacional de carne bovina. Será apresentado, um histórico desta tecnologia, além de uma discussão de suas vantagens e desvantagens. Atualmente, alguns países produtores como a Austrália, Estados Unidos, Canadá e consumidores como o Japão e alguns países da União Européia tiveram de intensificar o controle de qualidade do produto ao longo da cadeia produtiva. Para isso, têm utilizado novas tecnologias para rastrear seus produtos, a fim de atenderem às exigências dos mercados externo e interno. Entre estas tecnologias encontra-se a RFID. O artigo demonstra que, embora esta tecnologia seja potencialmente aplicável e traga inúmeras vantagens aos agentes que a utilizarem, a sua aplicação na prática ainda suscita discussões e dúvidas, principalmente quanto ao seu custo de implementação.
\end{abstract}

Palavras-chave: tecnologia da informação; cadeia produtiva bovina; rastreabilidade, RFID.

\section{Introdução}

A rastreabilidade pode ser entendida como "a capacidade de detectar a origem e de seguir o rastro de um gênero alimentício, de um alimento para animais, de um animal ou de uma substância, destinados a ser incorporados em alimentos para animais, ou com probabilidade de o ser, ao longo de toda fase de produção, transformação e distribuição.” (REG (EC) $n^{\text {o. }} 178$ de 2002, art. 3)

Uma tecnologia que pode ser potencialmente utilizada para efetuar a rastreabilidade, principalmente na produção agropecuária e no varejo de alimentos é a Identificação por Rádio Freqüência (Radio Frequency Identification - RFID). A aplicação do RFID para a etapa do processamento de alimentos, é de natureza mais complexa. A RFID é um método de identificação 
que usa ondas de rádio. O seu funcionamento ocorre por intermédio de um leitor que se comunica com uma etiqueta, a qual armazena informação digital em um microchip (SCHERER, DIDONET, LARA, 2004).

O objetivo deste artigo é descrever e discutir o uso da RFID para a rastreabilidade na cadeia de carne bovina no mundo. Serão apresentados os casos dos Estados Unidos, Canadá, Austrália, Japão e Europa.

Este artigo se divide em cinco capítulos. O primeiro é a introdução, em que se apresenta o trabalho, seus objetivos e os temas principais. O segundo descreve o método, abordagem e instrumentos de pesquisa utilizados para o desenvolvimento do trabalho. O terceiro possui a revisão de literatura sobre a cadeia produtiva bovina e a tecnologia da informação, a RFID. O quarto descreve o surgimento da necessidade do uso da RFID, o contexto e a legislação existentes nos países descritos acima para a pesquisa.

\section{Método de pesquisa}

Este artigo utiliza uma abordagem qualitativa e exploratória para atingir seus objetivos. Foi realizada uma pesquisa bibliográfica sobre o tema. A escolha dos casos que serão apresentados é o resultado desta pesquisa. Os critérios para a seleção dos casos (países) discutidos foram baseados, fundamentalmente, na disponibilidade de um conjunto de informações oferecido pela bibliografia consultada. Foram investigadas informações quanto à existência de iniciativas concretas do uso da referida tecnologia em algum elo da cadeia produtiva da carne bovina, assim como o contexto do país onde e quando ela foi implantada e a legislação existente relacionada ao seu uso. O período de pesquisa foi de outubro de 2006 a fevereiro de 2007.

\section{Cadeia Produtiva Bovina (CPB) e a Tecnologia da Informação}

Segundo Schiefer (2002), o setor de carne é caracterizado por um número de especificidades que põem pressão no setor para implementar conceitos de gerenciamento integrado em ambos níveis simultaneamente, tanto no nível da empresa, quanto no nível da cadeia; e tornam a implementação dos conceitos de gerenciamento uma iniciativa difícil de ser realizada.

Este setor tem como etapas os insumos, a criação de animais, a comercialização/engorda, os frigoríficos, o varejo e o consumidor final. A integração dos agentes desta cadeia nessas etapas é dificultada por os produtores rurais não se integrarem à agroindústria. Este problema causa outros mais sérios, como a ocorrência de doenças, como a febre aftosa, que causa prejuízos desde os produtores até os setores de transportes e embalagem, reduzindo a rentabilidade de grande parte da 
cadeia (COSTA, ZANINE E LÍRIO, 2005).

\subsection{Produção, exportação e consumo}

Há, atualmente, no rebanho bovino mundial cerca de 1,340 milhões de cabeças e sua evolução apresenta significativa estabilidade, tendo crescido apenas 0,26 \% em dez anos, de acordo com dados da Organização para a Alimentação e a Agricultura (Food and Agriculture Organization of the United Nations - FAO) (BUAINAIN e BATALHA, 2006). Como destaque, os cinco primeiros países que se destacam em rebanho são: Brasil, Índia, China, Estados Unidos e Argentina.

De acordo com os referidos autores, os maiores rebanhos por si só não caracterizam o melhor desempenho em produção de carne bovina. Destaca-se que, tomados individualmente, apenas treze dos vinte países que possuem os maiores rebanhos estão entre os vinte maiores produtores de carne em 2004 e nove países em 2005.

Quanto ao comportamento das exportações, as vendas brasileiras ao exterior de carne bovina apresentaram um crescimento médio significativo de $25 \%$ a.a. até 2005 e as exportações estadunidenses apresentaram uma queda acentuada com um decréscimo médio de 8,65\% como decorrência da eclosão da doença da vaca louca (Bovine Spongiform Encephalopathy - BSE) em 2002.

No item consumo, o único país a apresentar forte queda de consumo individual é a Argentina, seguindo de forma menos acentuada o Brasil. Depreende-se que isso possa estar associado aos preços mais competitivos do mercado mundial que induziram ao crescimento das exportações, elevando os preços internos e retraindo a demanda interna.

\subsection{Rastreabilidade}

Segundo Felício (2001), rastreabilidade é acompanhar o trajeto de indivíduos, serviços ou veículos. Na união da rastreabilidade com o controle e segurança alimentar na cadeia da carne bovina, pode-se utilizar brincos e colar de plástico, etiquetas com códigos de barras, marcação a ferro quente e a ferro frio com tinta spray e placas de alumínio para identificação noturna, para estudos de comportamento do animal (MACHADO e NANTES, 2004).

Para a identificação eletrônica, tem-se a telemetria que, com implantes eletrônicos, acionados a distância, emitem um sinal eletromagnético com a numeração do animal. Este sinal é recebido por um sistema de computação que confere rápida e inquestionavelmente a presença do animal naquele rebanho por rádio freqüência (PIRES, 2002).

No caso específico da carne bovina, com o diagnóstico da BSE em março de 1996, a 
posterior hipótese de relação entre esta doença do gado e da doença de Creützfeld-Jacob (CJD2), como uma nova variação de distúrbio similar em seres humanos, a rastreabilidade tornou-se foco tanto para produtores, quanto para consumidores no mundo inteiro (WIEMERS, 2000 In PIRES, 2002).

\subsection{TI: o uso da RFID}

A RFID é uma tecnologia de identificação automática com habilitação para comunicação sem fio (leitura e escrita sem contato direto) (AL-MOUSAWI, 2004:6).

$\mathrm{Na}$ cadeia produtiva da carne bovina esta tecnologia tem sido utilizada no gerenciamento de propriedades rurais, na alimentação automática e no registro de dados, como identificação eletrônica desde os anos 70. A primeira geração dos transponders (que é a etiqueta que faz parte do conjunto da tecnologia RFID) tinha como apresentação caixas pretas eletrônicas, anexadas em colares, que eram colocados no pescoço dos animais. A segunda geração de transponders veio com a miniaturização da eletrônica, permitindo o desenvolvimento de microchips muito pequenos, que puderam ser injetados sob a pele, além de possibilitarem a redução de custos. A terceira geração de transponders, em desenvolvimento, inclui, além de todas as possibilidades anteriores, a leitura e gravação, objetivando armazenar o histórico de vida do animal e a tecnologia dos sensores, monitorando a saúde e o desempenho do animal (MACHADO e NANTES, 2004).

\subsection{RFID: conceito, uso atual, benefícios e dificuldades}

Wyld (2006) cita três elementos necessários para a RFID trabalhar, que são: etiquetas, leitores e um software para unir os componentes da tecnologia para um sistema de processamento de informação amplo. O funcionamento ocorre desta forma: o leitor envia um sinal de rádio e a etiqueta responde com a sua própria identificação; o leitor, então, converte as ondas de rádio retornadas de uma etiqueta em um sistema de processamento de informação para filtrar, categorizar, analisar e disponibilizar a ação, baseada na identificação da informação proveniente da etiqueta.

O mesmo autor coloca que existem três componentes essenciais da etiqueta da RFID: o chip, a antena e a embalagem que os contem. A RFID pode ter várias formas: etiquetas pequenas, chaves, chaveiro, relógios, cartões, discos e moedas, com uma parte de metal entre a etiqueta e o item para reduzir a interferência e melhorar a leitura. Além desses formatos, pode-se encontrar transponders de vidro, que podem ser implantados sob a pele de animais e seres humanos (WYLD, 2006).

Segundo Gutierrez, Filha e Neves (2005), as etiquetas podem ser classificadas como ativas ou passivas. As primeiras têm fonte interna de energia que as alimenta, já as segundas, não. Por as 
etiquetas passivas possuírem preço bem inferior em relação às etiquetas ativas, espera-se sua adoção em maior escala no curto prazo.

Malone (2004) apresenta uma terceira categoria de etiquetas, as semi-passivas, onde a RFID possui um sensor que a habilita a rastrear o ambiente, monitorá-lo.

Gutierrez, Filha e Neves (2005) classificam, também, as etiquetas como: somente leitura, quando elas são gravadas uma só vez e que sua leitura pode ocorrer múltiplas vezes; e de leitura e gravação, onde os dados podem ser gravados e lidos múltiplas vezes.

Quanto à freqüência, podem ser quatro, cada qual com suas propriedades, tendo várias razões para serem usadas em aplicações específicas. As freqüências podem ser: baixa, 100-500kHz (a mais usada é entre 125-134 kHz), alta (13.56 MHz), ultra alta (UHF, 400-1000MHz, com uso mais freqüente entre $850-950 \mathrm{MHz}$ ) e microwave, 2.4-6.0 GHz (entre $2.45 \mathrm{GHz}$ ou $5.8 \mathrm{GHz}$ ).

Para Taillieu (2006), diferente dos códigos de barra que identificam todos os produtos e são lidos por feixe de luz, as etiquetas RFID identificam as embalagens individualmente e usam ondas de rádio, que podem ser lidas através de uma carteira, bolsos e até mesmo veículos. Além disso, não é necessária mira perfeita para a leitura no caso da etiqueta da RFID, ela pode ser lida por meio de materiais não-metálicos, muitas podem ser lidas simultaneamente, são resistentes a determinadas temperaturas e outros fatores externos e podem ser lidas e reprogramadas até 300.000 vezes (DEJONG, 1998 In KÄRKKÄINEN, 2003). Quando são utilizadas em containers recicláveis, as mesmas etiquetas podem ser usadas várias vezes.

As dificuldades da RFID estão relacionadas a questões éticas, como, por exemplo, o consumidor participar, involuntariamente, de pesquisa de hábito de compras, entre outros. Para assegurar que estes problemas não ocorram, a EPCGlobal, que é a instituição que determina os padrões das etiquetas, recomenda que os dados contidos nas etiquetas sejam apagados quando o produto for adquirido (WYLD, 2006).

Há ainda outros problemas que podem existir, relacionados à presença de água ou metal, que podem fazer com que a taxa de leitura decline. Isto ocorre porque líquidos absorvem as ondas de rádio e os metais as refletem. Produtos como frutas, cerveja e vinho podem ter mais problemas com as etiquetas, mas não significa afirmar que não podem ser etiquetados com a tecnologia RFID.

Os custos também são fatores impeditivos, os preços das etiquetas variam de US\$ 0,50 a US\$ 150,00, dependendo das funções embutidas. Contudo, de acordo com Gutierrez, Filha e Neves (2005), o custo total de implementação é compensado por ganhos em produtividade e reduções de perdas associadas ao processo a ser acompanhado (SAYER, 2006). 


\section{Uso de RFID na Cadeia Produtiva Bovina Internacional}

\subsection{Estados Unidos}

- Contexto

A descoberta de uma vaca em uma cidade dos EUA com a doença denominada popularmente como 'vaca louca' (BSE) gerou, no início de 2003, um grande interesse na tecnologia RFID para rastrear o gado e outros rebanhos no país.

Em outubro de 2004, o Food and Drug Administration (FDA) aprovou o primeiro chip RFID para ser implantado em seres humanos. Estes chips podem unir informação pessoal de saúde, cartão de crédito pessoal e informações bancárias, senhas e códigos especiais ou qualquer outra informação sobre um indivíduo (TAILLIEU, 2006).

No setor de carne onde grande número de produtos poderia ser feito de forma mais uniforme e focada nos atributos desejados pelos consumidores, pode-se resolver problemas de segurança alimentar que, embora possa elevar seu custo de produção, será compensado pela manutenção dos níveis de consumo (TRONSTAD e UNTERSCHULTZ, 2005).

\section{- Legislação}

Em 2003, foi criado um Ato contra a invasão da privacidade aos consumidores em relação ao uso da RFID pelos varejistas, o Right to Know Act of 2003. Esses consumidores se uniram e criaram uma entidade denominada de Consumers against Supermarket Privacy Invasion and Numbering (CASPIAN) e rascunharam este Ato, que busca aperfeiçoar questões relacionadas à embalagem, etiquetas e produtos como cosméticos e álcool (IBRAHIM, 2005).

Atualmente, doze estados possuem alguma forma de legislação a respeito do uso da tecnologia RFID. Eles objetivam criar um grupo para estudar a tecnologia em Maryland, a fim de impedir que o governo obrigasse os cidadãos a terem um chip desta tecnologia sob suas peles em Wisconsin, Dakota do Sul e New Hampshire.

\subsection{Canadá}

\section{- Contexto}

No Canadá foi realizada uma pesquisa pela Deloitte \& Touche em 2004, denominada de Estudo da Rádio Freqüência canadense" entre os altos executivos dos 30 maiores grupos de varejo do país e obteve-se estes resultados: 93\% dos entrevistados acreditam que a RFID impactará seus negócios; 47\% estão prontos para implementar um sistema de rastreabilidade com RFID na sua 
empresa, com metade deles pretendendo fazê-lo nos próximos dois anos e 29\% nos dois anos seguintes; 71\% são pró-ativos quando considerada a implantação de uma RFID. Assim como em outras pesquisas, metade dos entrevistados respondeu que o maior obstáculo é o custo (http://www.rfidupdate.com/articles/index.php?id=645).

Em dezembro de 2001, John Manley que era o primeiro ministro do Canadá, junto com Tom Ridge, Diretor de Segurança dos EUA fizeram um acordo denominado de Declaração dos 30 pontos da Fronteira Inteligente. O acordo incluía, entre outras coisas, a promessa de introduzir cartões de identificação por rádio freqüência, identificadores biométricos na documentação (marcadores de DNA, identificação por retina, impressão digital), cartões permanentes, listas de pessoas impedidas de voar e de renovar seus passaportes, legislação anti-terrorista, entre outras determinações. O problema deste acordo é que, para a população, soou como algo ditatorial, sem a participação pública.

\section{- Legislação}

Quanto à legislação, o que pode estar impedindo que a questão da privacidade do consumidor seja discutida de forma mais clara e objetiva são os resultados que a implantação da RFID representa. A Associação de Marketing Canadense estima que 480 mil empregos, que geram 51 bilhões de dólares canadenses em vendas, anualmente, estão envolvidos na coleta desta informação, analisando a base de dados do consumidor e intermediando essa troca de informação (TAILLIEU, 2006).

Para maior proteção do consumidor e para permitir uma convivência melhor entre a tecnologia e a ética, o país possui o Personal Information Protection and Electronic Documents Act (PIPEDA), que norteia a coleta, uso e desdobramento da informação pessoal junto a empresas em atividades comerciais. Porém, não há uma anuência com relação às leis, como, por exemplo, os varejistas que atuam na Internet e que não estão de acordo com o PIPEDA. Isto leva ao uso de informações dos consumidores que, de certa forma, não concordam e ainda não possuem meios de coibir este uso.

\subsection{União Européia (UE)}

\section{- Contexto}

Com os problemas relacionados à segurança do alimento, como a crise da vaca louca, em vários países da Europa, a RFID foi necessária no Reino Unido. O primeiro caso de vaca louca identificado foi publicado em novembro de 1986, Inicialmente, os casos cresceram rapidamente, atingindo seu ápice em 1992, com 36.681 animais infectados. Após este crescimento preocupante, 
houve um declínio rápido para 7.751 casos em 1996. Em setembro de 1996 foi criado o Scottish Border TAG (Traceability and Assurance Group), uma iniciativa para os fazendeiros seguirem, que incluía rastreabilidade total e conseqüente segurança do alimento ofertado (CALDER e MARR, 1998).

Esses problemas relacionados à saúde animal adicionados ao cancelamento dos subsídios aos produtores após 2005 levaram a mudanças, também, no hábito do consumidor, que de 1980 a 2002 teve um decréscimo do consumo da carne bovina per capita, de 20,9 kg para 16,6 kg. Além disso, houve uma concentração de mercado de oferta do produto, com $75 \%$ de carne fresca sendo vendida pelos varejistas (COX e CHICKSAND, 2005, p. 648).

Quanto à segurança e controle dos cidadãos no final de outubro de 2004, os ministros dos países membros da União Européia aceitaram o uso dos passaportes biométricos com a emissão dos primeiros até 2006. Estes passaportes são dotados de um chip RFID que, além da identificação do portador (nome, filiação, data e país de nascimento etc) contem, inicialmente, sua foto digitalizada e dados faciais. Até este ano, o chip conterá também a impressão digital digitalizada.

\section{- Legislação}

A União Européia tem explorado formas de proteger a privacidade de cidadãos com atenção às informações pessoais, usando a RFID. A união criou um grupo de trabalho que em meados de janeiro, publicou seu primeiro trabalho, o Working Document 105 (SULLIVAN, 2005). O documento tem uma variedade de aplicação em vários setores de negócios, incluindo saúde, varejo, farmacêutico e de logística.

O referido grupo de trabalho enfatiza que existe uma necessidade de uma pesquisa adicional sobre a criptografia, que pode proteger a informação pessoal nas etiquetas. Isto impede que a etiqueta relacione os dados do consumidor com o produto que ele comprou. Para passaportes e outros documentos de identificação que não podem ser alterados, o grupo sugere que se use uma autenticação padronizada vinda da ISO, que fará criptografia da informação e tornará o acesso às informações do consumidor indisponível às pessoas sem esta autorização.

\subsection{Austrália}

\section{- Contexto}

Em 1996, 25 fazendas tiveram problemas com a detecção de níveis excessivos de uma substância tóxica e, após este evento, a etiqueta passou a ter uma regulamentação, a National Vendor Declaration (NVD), que incluía algumas questões de segurança para o proprietário dos animais. 
A mais recente atualização dos instrumentos de identificação na Austrália ocorreu com a implementação do National Livestock Identification System (NLIS). Este é um sistema de identificação permanente e permite que um animal individual seja rastreado desde seu nascimento na propriedade até sua destinação a um frigorífico.

Cada transação pela qual o animal passa é registrada, estas informações criam um histórico dos movimentos de cada animal, desenvolvendo uma base de dados eletrônica para facilitar a rastreabilidade individual em todo o rebanho do país. A base de dados central é mantida pela Meat\&Livestock Austrália (MLA), um serviço privado fundado pela indústria a partir de arrecadações dos produtores de gado vindas de cada transação dos animais.

Os sete estados do país tiveram que implementar o NLIS até 1 de julho de 2005 e, até esta data, todos eram livres para escolher qual o melhor dia para realizar a implementação. Um ano após esta data, no estado de Vitória, todos os animais tinham sido identificados com os dispositivos aprovados pelo NLIS.

\section{- Legislação}

O Senado australiano aprovou uma lei de passaportes rígida para o uso de biométrica facial, para a RFID e para a troca de dados. De acordo com o então Ministro das Relações Exteriores, Alexander Downer, a legislação - planejada para ser efetivada em 1 de julho de 2005 - proveria um suporte ao governo para combater as fraudes de identidades falsas. Contudo, enquanto o governo federal afirma que com esta legislação o povo estará mais protegido, os democratas e advogados privados discordam. Eles questionam a questão da segurança e afirmam que a única função da etiqueta inteligente é localizar a pessoa (IBRAHIM, 2005).

\subsection{Japão}

\section{- Contexto}

Com problemas relacionados a doenças como a vaca louca, além de uma série de problemas relacionados a doenças de animais para consumo, a confiança dos consumidores japoneses foi afetada quanto à segurança de seu alimento fornecido. $\mathrm{O}$ governo japonês tem respondido a essa demanda com a implementação de uma série de novas regulamentações e com a criação de uma Comissão nova, a de Segurança do Alimento. A indústria de alimentos tem respondido com programas de seguro, para reduzir a ansiedade do consumidor sobre a segurança do alimento e tudo o que se relaciona a este item.

Muitos destes programas de seguros e destas novas regulamentações são baseados, em parte, em sistemas de rastreabilidade. Contudo, tentativas que requerem rastreabilidade de carne 
importadas não têm obtido o resultado esperado. Apesar disso, muitos especialistas acreditam que a rastreabilidade terá uma função importante no gado japonês e na indústria de processamento de carne (CLEMENS, 2003).

\section{- Legislação}

Em julho de 2002 foi sancionada uma lei relacionada a uma contramedida especial à vaca louca. A lei requer uma rastreabilidade para o gado desde a fazenda até a instalação de beneficiamento. Estas informações são inseridas dentro do registro de família do rebanho doméstico.

Em junho de 2003, a legislação japonesa aprovada exigia rastreabilidade desde a fazenda até o varejista. Sob a nova lei, processadores, distribuidores e varejistas já em 2004 demandavam informações desde o frigorífico até o varejista. A lei inclui partes da carne, mas exclui partes como vísceras, acompanhamentos, produtos processados e etc. Os atacadistas e os varejistas podem obter informação de animais individuais ou dos lotes e existirão penalidades para os que não cumprirem as determinações das regulamentações. O governo auxiliará as empresas com baixas taxas de juros para financiamentos e créditos, cobrindo o custo do computador e as tecnologias da etiqueta requeridas para implantar o sistema.

No mesmo período, o Ministério da Agricultura, Floresta e Pesca anunciou um novo Padrão Japonês de Agricultura (JAS), que consiste em um programa de certificação de rastreabilidade de carne importada. O JAS é voluntário, a carne doméstica é também elegível para a certificação se seu produtor tiver as informações de fornecedores de alimentos e fármacos. Esta certificação já era esperada para o ano de 2004.

\section{Conclusão}

Para haver o controle de qualidade e sanidade da carne bovina, têm sido utilizados alguns recursos nas fazendas, como brincos identificadores do gado, entre outros. Porém, estes brincos não são suficientes para o rastreamento total das características dos animais e do transporte destas informações pela cadeia de suprimentos. Com o objetivo de se rastrear estes animais, de obter-se informações mais detalhadas a seu respeito, de forma individual e não em lotes, utiliza-se a RFID. Nos países pesquisados pôde-se observar que aqueles que ainda não o utilizam, estão em processo de implantação, seja por motivos de segurança nacional (EUA), seja por motivos comerciais (Canadá).

Esta implantação tem como estímulo o acesso a informações detalhadas e o fato de as etiquetas serem mais resistentes, em comparação com os códigos de barra. As vantagens são 
inúmeras, mas há também desvantagens, como a questão do custo, os problemas com a privacidade do consumidor e o desemprego que poderá ser elevado com a substituição de pessoas que trabalham em pontos de venda nos supermercados (PDVs) por equipamentos de leitura.

As questões técnicas também estão relacionadas aos padrões, em que prevalece os da EPCGlobal, da ISO, para o uso e aplicação da tecnologia. Contudo, esta discussão ainda permanecerá por um tempo, já que deve haver uma unificação de alguns padrões e também para os países em desenvolvimento como o Brasil, em que se segue o primeiro padrão, o EPCGlobal, mas que deveria ter um padrão para a realidade brasileira.

\begin{abstract}
This paper aims to discuss the use of Radio Frequency Identification (RFID) in the international cattle chain traceability. It will be presents historical things about the technology and your advantages and disadvantages. Nowadays, some countries have to intensify the quality control in some operations in a cattle chain. Some of them are producers (as Australia, United States, Canada) and some of them are consumers (as Japan and some of European Union). These countries have been used news technologies to trace their products to attend their markets (domestic and external). One of these technologies is RFID. This paper shows that although this technology is efficient to be used and carries with it a lot of advantages to agents in a cattle chain that will use it, it produces discussions and doubts, mainly about its cost.
\end{abstract}

Keywords: Information Technology, meat chain, traceability, RFID.

\title{
Referências
}

AL-MOUSAWI, H. Performance and reliability of Radio Frequency Identification (RFID): theoretical evaluation and practical testing in relation to requirement from use in Abu Dhabi Sewerage. Junho, 2004. 107p. Dissertação (Mestradoem Tecnologia da Informação e Comunicação) - Agder University College, Faculty of Engineering and Science, Grimstad, Norway, 2004.

BUAinain, A. M.; BAtalHA, M. O. Análise da Competitividade das Cadeias Agroindustriais Brasileiras. UFSCar; Unicamp, 2006. Projeto MAPA/IICA.

CALDER, R.; MARR, P. Insights from industry. A beef producer initiative in traceability: Scottish Borders TAG. Supply Chain Management. MCB University Press. v.3, n.3, p. 123-126, 1998.

CLEMENS, R.. Meat traceability in Japan. Review Paper (IAR 9:4:4:4-5). Agricultural marketing resource center. Center for Agricultural and Rural Development. November 2003.Iowa State University. Ames, Iowa, EUA.

COX, A.; CHICKSAND, D. The limits of lean management thinking: multiple retailers and food and farming supply chains. European Management Journal, v. 23, n. 6, p. 648-662, dez. 2005.

cross ${ }^{\text {ref }}$

GUTIERREZ, R. M. V.; FILHA, D. C. M.; NEVES, M. E. T. M. S.. Complexo eletrônico: identificação digital por radiofreqüência. Complexo Eletrônico. BNDES Setorial, Rio de Janeiro, n. 22, p.29-70, set. 2005.

IBRAHIM, T. A Study of RFID Privacy \& Security. Department of Computer Science and Computer Engineering. University of Arkansas, Fayetteville. 2005. Term Project - Fall 2005.

KÄRKKÄINEN, M. Increasing efficiency in the supply chain for short shelf life goods using RFID tagging. International Journal of Retail\&Distribution Management. EUA, v. 31, n. 10. p. 529-536, 2003. 
MACHADO, J. G. de C. F.; NANTES, J. F. D. Identificação eletrônica de animais por rádio-freqüência (RFID): perspectivas de uso na pecuária de corte. Revista Brasileira de Agrocomputação, v. 2, n. 1, p. 29-36, jun. 2004. Ponta Grossa, PR, DEINFO/UEPG.

MALONE, R. Sensing the future. Inbound Logistics, v. 24, n.12, p. 18-19, 2004.

PIRES, P. P. Identificação e gerenciamento eletrônicos de bovinos. I Conferência Virtual Global sobre Produção Orgânica de Bovinos de corte. Embrapa. 02 de set.-15 de out. de 2002. p. 1-4.

REG (EC) n $n^{\text {o. }} 178$ de 2002, art. 3

SAYER, P. European Commission to launch public inquiry into RFID. Will examine privacy and security issues raised by use of radio tags. 09 de março de 2006. Disponível em http://www.computerworld.com/softwaretopics/erp/story/0,10801,109365,00.html. Acesso em: 04 jan. 2007.

SCHERER, F. L.; DIDONET, S. R.; LARA, J. E. Considerações sobre a utilização de etiquetas inteligentes no varejo. In: VII SEMEAD, 2004. FEA/USP. Anais do VII SEMEAD, SP, 2004.

SCHIEFER, G. Environmental control for process improvement and process eficiency in supply chain management the case of the meat chain. International Journal of Production Economics, v. 78, p. 197-206, 2002.

cross ${ }^{\text {ref }}$

Sullivan, L. The European Union Works Out RFID Privacy Legislation. Fevereiro, 2005. Disponível em http://informationweek.com/story/showArticle.jhtml?articleID=59301363 Acesso em: 20 dez. 2006.

TAILLIEU, M. Radio Frequency Identification and the need to protect personal information. Disponível em http://www.parl.gc.ca/Infoparl/english/issue.htm?param=179\&art=1213 Acesso em: 16 jan. 2007.

TONSOR, G. T.; SCHROEDER, T.C.. Australia's livestock identification systems: implications for United States Programs. Agosto de 2004. Disponível em http://agmanager.net/events/risk_profit/2004/Schroeder.pdf Acesso em: set. 2006.

TRONSTAD, R.; UNTERSCHULTZ, J. Looking beyond value-based pricing of beef in North America. Supply Chain Management: an International Journal, v. 10, p. 214-222, março 2005.

WYLD, D. C. RFID 101: the next big thing for management. Management Research News, v.29, n.4, 2006.

STRONG demand for RFID in Canada. 15 de novembro de 2004. Disponível em http://www.rfidupdate.com/articles/index.php?id=645. Acesso em: 05 jan. 2007.

\section{Dados dos autores}

Nome completo: Priscilla Cristina Cabral Ribeiro

Filiação institucional: Universidade Federald e Ouro Preto - UFOP

Universidade Federal de São Carlos - UFSCar

Departamento: Depto. de Engenharia de Produção, Administração e Economia, Escola de Minas, Univbersidade Federal de Ouro Preto-UFOP/

Depto. de Engenharia de Produção-PPGEP-Universidade Federal de São CarlosUFSCAR

Função ou cargo ocupado: Professora assistente (UFOP)/doutoranda (UFSCAR) 
Endereço:Rua Paulino Botelho de Abreu Sampaio, 1057, ap.11-A.Vila Pureza, São Carlos, SP, BRASIL - CEP 13561-060.

Telefones para contato: (16) 3372-6085/8114-6879/ 3351-8236 R. 9237 (FALAR COM CRISTIANE)

e-mail: priscilla@depro.em.ufop.br

Nome completo: Annibal José Scavarda

Filiação institucional: School of Management, Royal Melbourne

Institute of Technology University

Departamento: MANAGEMENT

Função ou cargo ocupado: PROFESSOR (LOGISTICA)

Endereço completo: Building 108, Level 16, 239 Bourke Street Melbourne GPO OX 2476V, Melbourne VIC 3001 Australia

Telefones para contato: +61399251312

e-mail: annibal@rdc.puc-rio.br

Nome completo: Mário Otávio Batalha

Filiação institucional: Universidade Federal de São Carlos - UFSCar

Departamento: Departamento de Engenharia de Produção/PPGEP

Função ou cargo ocupado: Professor Associado

Endereço completo para correspondência: Rod. Washington Luís - Km 235, São Carlos, São Paulo Brasil CEP: 13565-905

Telefones para contato: 16 3351-8236 - R.9229 OU 9237 (falar com Cristiane)

e-mail: $\underline{\text { dmob@power.ufscar.br }}$ 